CLINICAL PRACTICE

\title{
Starch safety in resuscitation - when will we ever learn?
}

\author{
A Parrish, M Blockman \\ Andy Parrish has in interest in evidence-based medicine, works in the Department of Internal Medicine, Frere and Cecilia Makiwane hospitals, East \\ London, and is affiliated to Walter Sisulu University, Rhodes University and the University of Cape Town, South Africa. \\ Marc Blockman has an interest in drug policy and evidence-based medicine and works in the Department of Internal Medicine, Division of Clinical \\ Pharmacology, Groote Schuur Hospital and University of Cape Town, South Africa.
}

Corresponding author: A Parrish (andygp@mweb.co.za)

Recent trials have failed to demonstrate a survival benefit from the use of hydroxyethyl starches (HES) as a colloid in fluid resuscitation and have raised concerns of renal harm. In severe sepsis, there is a concerning signal of increased mortality. New high-quality systematic reviews consistently demonstrate a statistically non-significant relative risk of death of $1.08-1.10$ and a significant $25 \%$ increased chance of requiring renal replacement therapy. The HES literature contains many industry-affiliated reviews of indifferent quality. Traditional efficacy confidence limits may warrant re-evaluation when considering these harms. Newer formulations of HES and more focused indications for use show benefit on surrogate endpoints, but these trials are currently underpowered to ensure safety.

S Afr Med J 2013;103(6):365-367. DOI:10.7196/SAMJ.6969

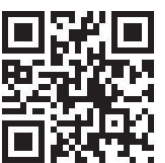

The recent publication of several large wellconducted trials on hydroxyethyl starch (HES) has led to a re-examination of evidence for colloids in medicine. A Cochrane review ${ }^{[1]}$ showed no mortality advantage from HES, albumin, modified gelatins or dextran when compared with crystalloids. A 2011 review of $\mathrm{HES}^{[2]}$ raised concerns of increased harm, particularly with older HES formulations, and this concern was reiterated in a 2013 review. ${ }^{[3]}$ In a recent editorial ${ }^{[4]}$ it was suggested that the accrued evidence now allows us to declare that starches have reached the 'end of the road' in the care of critically ill patients with sepsis.

In such patients the baseline mortality rate can be as high as $40 \% \cdot{ }^{[5]}$ Even assuming half that $(20 \%)$, a relative risk of 1.09 gives an absolute mortality increase of $1.8 \%$, or one extra death for every 56 high-risk patients prescribed HES as used in the underlying trials. The South African (SA) public sector spent R45 million on HES in 2011 (pharmaceutical directorate, personal communication). If HES was used in a similar way to that in the sepsis trials, this might mean several hundred excess deaths annually in this country alone.

\section{The new trials}

The CHEST study ${ }^{[6]}$ compared 90-day mortality in 7000 patients admitted to intensive care units (ICUs) and resuscitated with either $6 \%$ HES $130 / 0.4$ or saline. The two groups had similar mortality rates, but more patients in the HES group required renal replacement therapy $(7.0 \%$ v. $5.8 \%$; relative risk (RR) $1.21,95 \%$ confidence interval (CI) 1.00 - 1.45). Patients in the $6 \mathrm{~S}$ study ${ }^{[5]}$ had severe sepsis and were given $6 \%$ HES 130/0.42 or Ringer's acetate. Mortality at 90 days in the 398 patients in the HES group was $51 \%$, while it was $43 \%$ in the 400 assigned to Ringer's acetate (RR 1.17, 95\% CI 1.01 - 1.36). At 90 days, more patients in the HES group needed renal replacement therapy (22\% v. $16 \%$; RR 1.35 , $95 \%$ CI $1.01-1.80)$.

The same pattern was seen in the 196-patient CRYSTMAS study, ${ }^{[7]}$ which was only powered to detect a difference in volumes infused between 6\% HES 130/0.4 and saline in patients with sepsis. The product manufacturer was involved in the design, analysis and writeup of the study. The 90-day mortality was non-significantly higher in the HES group ( $40 \%$ v. $33 \%$ using intention to treat data; RR 1.2 , $95 \%$ CI 0.83 - 1.74).

$\operatorname{VISEP}^{[8]}$ (2008) compared the older 10\% HES 200/0.5 with Ringer's lactate in 537 patients with severe sepsis. Total HES volumes infused were high, with a median cumulative volume of $70 \mathrm{ml} / \mathrm{kg}$, and the dose limit of $20 \mathrm{ml} / \mathrm{kg} /$ day was exceeded by more than $10 \%$ on at least one day in more than $38 \%$ of patients. The trial was stopped early because of increased renal failure and a trend to increased mortality in the HES group. Mortality at 90 days was $41 \%$ in the HES group and $33.9 \%$ in the control group (RR 1.21, 95\% CI 0.97 - 1.51). Renal replacement therapy was required in $31 \%$ of the HES group and in $18.8 \%$ of controls (RR 1.66, 95\% CI 1.22 - 2.25).

Further interesting studies await publication. The blinded 240-patient Basel study for the evaluation of starch infusion for septic patients $\left(\mathrm{BaSES}^{[9]}\right)$ was completed in May 2011. The unblinded 3000 -patient CRISTAL trial ${ }^{[10]}$ compared 'any colloid' with crystalloid. The latter trial was reported (International Symposium on Intensive Care and Emergency Medicine 2013) to show a statistically significant overall survival benefit from early colloid use, but the details await full publication and careful HES subgroup analysis.

\section{New systematic reviews}

There have been several recent high-quality systematic reviews (Table 1). The Cochrane review on colloids was updated in 2013. ${ }^{[1]}$ The RR of death in 15 trials of HES was 1.10 (95\% CI 1.02 - 1.19), and that in the Gattas review ${ }^{[11]}$ (third-generation HES products) was 1.08 (95\% CI 0.97 - 1.21). Most recently, Zarychanski et al. performed a high-quality systematic review of all HES products. ${ }^{[3]}$ The mortality RR was 1.09 (1.02 - 1.17) after excluding seven early trials by Boldt et al., whose research corpus must be regarded with caution after multiple retractions. ${ }^{[12]}$ The Haase review, ${ }^{[13]}$ looking only at a highly defined subset of starch trials (highquality trials, third-generation HES, sepsis), found a very similar RR of 1.11 but with an expected wider CI (1.00 - 1.23). 'Multiplelook' meta-analyses increase the risk of false-positive results, which was addressed in this review using trial sequential analysis (wider 95\% CI 0.95 - 1.29). None of the other patient-relevant 
clinical endpoints, such as length of ICU stay, use of mechanical ventilation or presence of major bleeding, showed a statistically significant advantage of HES over crystalloids.

\section{Renal harm}

Both the Gattas ${ }^{[1]}$ and Zarychanski ${ }^{[3]}$ reviews found convincing evidence of renal harm. In Gattas et al's review, there was a $27 \%$ relative increase in the need for renal replacement therapy in patients given HES compared with crystalloid (RR 1.27, 95\% CI 1.10 - 1.46). The equivalent RR in the Zarychanski review was 1.32 (95\% CI 1.15 - 1.50) where the control intervention was not always crystalloid.

\section{Assessing the potential for harm}

Formal assessment of harm is complex, and may be unfamiliar to clinicians without expertise in pharmaco-epidemiology. Convincing safety signals usually require large numbers in the numerator, and registration trials are underpowered for this. Patient numbers several times higher than those used in efficacy trials are required. Accrual of harms may not proceed at the same rate as benefits, so acute resuscitation trials with short-term endpoints will not detect harms taking weeks to accrue. An appropriate comparator is important pooling trials where some control groups were given other colloids rather than crystalloids dilutes harm signals.

The 0.05 type I error rate used to measure the certainty of an effect is purported to have originated with Fischer ${ }^{[14]}$ and was adopted by the Food and Drug Administration (FDA) ${ }^{[15]}$ and other medicines regulators. It makes sense to minimise the probability of a false-positive statement when determining efficacy. However, do we need to be $95 \%$ sure of danger before avoiding a course of action? ${ }^{[16]}$ Table 2 illustrates the effect of changing type 1 error rates on statements of certainty.

Unlike the albumin controversy, where an earlier Cochrane review ${ }^{[17]}$ raised concerns about harm that were not confirmed in a subsequent large trial $\left(\mathrm{SAFE}^{[18]}\right)$, the current HES harm signal comes from information on more than 10000 patients and is robust.

\section{Scoring reviews versus keeping score of the number of reviews}

Manufacturers react appropriately to safety concerns by commissioning reviews. Guidelines on assessing the quality of a systematic review exist. ${ }^{[19]}$ High-quality reviews are reliable if the underlying trials are unbiased, and if adequate patient numbers have accrued. A 'review of reviews' on HES raises some concerns. ${ }^{[20]}$ The authors identified 165 reviews published between 1976 and 2010 , of which $7 \%$ contained a meta-analysis. Of the higher-quality reviews, $83 \%$ were not supportive of HES versus $20 \%$ of the lowerquality reviews. Of 124 positive reviews, 70 were written by only 14 experts, and 10 of these authors had identifiable potential conflicts of interest. An unsuspecting reader is more likely to encounter multiple low-quality positive reviews than the few high-quality ones. Simple repetition does not imply truth.

\section{Identifying industry influence}

It is helpful to identify reviews at risk of bias. Clues include finding authors with clear affiliations to HES manufacturers, reviews listing

Table 1. Hydroxyethyl starch reviews

\begin{tabular}{|c|c|c|c|c|c|c|c|c|}
\hline \multirow[b]{2}{*}{ Author } & \multirow[b]{2}{*}{ Date } & \multirow[b]{2}{*}{ Indication } & \multirow[b]{2}{*}{ HES type } & \multirow[b]{2}{*}{ Bias risk } & \multicolumn{2}{|c|}{ Mortality } & \multicolumn{2}{|c|}{ Renal harm* } \\
\hline & & & & & RR $(95 \%$ CI) & $\begin{array}{l}\text { No. of } \\
\text { studies (total } \\
\text { patients) }\end{array}$ & RR $(95 \% \mathrm{CI})$ & $\begin{array}{l}\text { No. of } \\
\text { studies (total } \\
\text { patients) }\end{array}$ \\
\hline Hartog et al..$^{[2]}$ & 2011 & $\begin{array}{l}80 \% \text { elective } \\
\text { surgery }\end{array}$ & $130 / 0.4$ & & Insufficient data & 56 & & \\
\hline 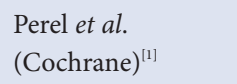 & 2013 & $\begin{array}{l}\text { 'Critically ill } \\
\text { patients' }\end{array}$ & All & Low & $1.10(1.02-1.19)$ & $15(9$ 147) & & \\
\hline Gattas et al. ${ }^{[11]}$ & 2013 & $\begin{array}{l}\text { 'Acutely ill } \\
\text { patients' }\end{array}$ & $\begin{array}{l}130 / 0.4 \text { or } \\
0.42\end{array}$ & Low & $1.08(0.97-1.21)$ & $10(8367)$ & $1.27(1.10-1.46)$ & $6(8141)$ \\
\hline Zarychanski et al. ${ }^{[3]}$ & 2013 & $\begin{array}{l}\text { 'Critically ill } \\
\text { patients' }\end{array}$ & All & Moderate & $1.09(1.02-1.17)$ & $28\left(\begin{array}{ll}10 & 290)\end{array}\right)$ & $1.32(1.15-1.50)$ & $10(9258)$ \\
\hline Haase et al ${ }^{[13]}$ & 2013 & Sepsis & $\begin{array}{l}130 / 0.38- \\
0.45\end{array}$ & $\begin{array}{l}\text { Low to } \\
\text { moderate }\end{array}$ & $1.11(1.00-1.23)$ & $4(3016)$ & $1.36(1.08-1.72)$ & $5(1311)$ \\
\hline
\end{tabular}

Table 2. Sensitivity analysis ${ }^{\star}$ of differences in type I error rate for a pooled effect size (mortality) from the three major trials (VISEP, ${ }^{[8]}$ CHEST $^{[6]}{ }^{[6} S^{[5]}$ )

\begin{tabular}{|c|c|c|c|}
\hline Confidence interval & Relative risk 1.10 & Risk difference 0.021 & Statistically significant \\
\hline $99 \%$ & $0.990-1.225$ & $-0.002-0.044$ & No \\
\hline $95 \%$ & $1.015-1.194$ & $0.003-0.038$ & Yes \\
\hline $90 \%$ & $1.029-1.178$ & $0.006-0.036$ & Yes \\
\hline $50 \%$ & $1.071-1.132$ & $0.015-0.027$ & Yes \\
\hline $33 \%$ & $1.082-1.121$ & $0.017-0.025$ & Yes \\
\hline
\end{tabular}


a manufacturer as sponsor or originator of a review, and reviews looking at endpoints where the focus is on physiological variables or other short-term surrogate markers rather than patient-relevant clinical measures. Missing features often include a clearly defined trial search strategy, and a table listing inclusions and exclusions, and the reasons for these. Lack of power to detect harm even after study pooling may be underemphasised. Measure of internal validity (trial quality scores) may be absent, and control groups inappropriate. Pooling methods may be unusual or use methods that do not take account of differences in baseline prevalence and trial size. ${ }^{[21]}$ The introduction and discussion sections may contain non-scientific 'emotive' words and product trade names.

For example, a 2013 industry-associated review ${ }^{[22]}$ of 17 studies of HES in surgical patients found 'no evidence of renal dysfunction'. Only 6 of these studies (a total of 437 patients) had a crystalloid comparator, trial quality was not formally reported, and there was evidence of heterogeneity.

\section{Conclusion}

Imagine another decade of HES use following current practice. If industry-associated opinion leaders are right, our patients would be unscathed. However, if the systematic reviews are correct, we would have ignored powerful signals of harm, and continued to expose our patients to a product that may increase mortality in sepsis, and may increase the need for dialysis in resuscitation. With these caveats, and in the absence of adequately powered studies to confirm safety in other situations, it is difficult to justify ongoing use of these products.

Conflict of interest. The authors have no financial or intellectual conflict of interest.

1. Perel P, Roberts I, Ker K. Colloids versus crystalloids for fluid resuscitation in critically ill patients. Cochrane Database Syst Rev 2013, Issue 2. Art. No.: CD000567. [http://dx.doi.org/10.1002/14651858. CD000567.pub6]
2. Hartog CS, Kohl M, Reinhart K. A systematic review of third-generation hydroxyethyl starch (HES 130/0.4) in resuscitation: Safety not adequately addressed. Anesth Analg 2011;112(3):635-645. [http:// dx.doi.org/10.1213/ANE.0b013e31820ad607]

3. Zarychanski R, Abou-Setta AM, Turgeon AF, et al. Association of hyroxyethyl starch administration with mortality and acute kidney injury in critically ill patients requiring volume resuscitation. JAMA 2013:309(7):678-688. [http://dx.doi.org/10.1001/jama.2013.430]

4. Prowle JR, Pearse RM. Is it the end of the road for synthetic starches in critical illness? BM] 2013:346:f1805. [http///dx doi.org/10.1136/bmj f1805]

5. Perner A, Haase N, Guttormsen AB, et al. Hydroxyethyl starch 130/0.42 versus Ringer' Perner A, Hase N, Guttormsen AB, et al. Hydroxyethyl starch 130/0.42 versus Ringer's
acetate in severe sepsis. N Engl J Med 2012;367(2):124-134. [http://dx.doi.org/10.1056/ acetate in severe

NEJMoa 1204242]
Myburgh JA, Finfer S, Bellomo R, et al. Hydroxyethyl starch or saline for fluid resuscitation in intensive care. N Engl I Med 2012;367(20):1901-1911. [http://dx.doi.org/10.1056/NEJMoa1209759]

7. Guidet B, Martinet O, Boulain T, et al. Assessment of hemodynamic efficacy and safety of $6 \%$ hydroxyethylstarch $130 / 0.4$ vs. $0.9 \% \mathrm{NaCl}$ fluid replacement in patients with severe sepsis: The CRYSTMAS study. Critical Care 2012;16(3):1-10. [http://dx.doi.org/10.1186/ccl1358]

8. Brunkhorst FM, Engel C, Bloos F, et al. Intensive insulin therapy and pentastarch resuscitation in severe sepsis. N Engl J Med 2008;358(2):125-139. [http://dx.doi.org/10.1056/NEJMoa070716]

9. ClinicalTrials.gov. http://clinicaltrials.gov/show/NCT00273728 (accessed 8 April 2013).

10. ClinicalTrials.gov. http:// clinicaltrials.gov/ct2/show/NCT00318942 (accessed 8 April 2013).

11. Gattas DJ, Dan A, Myburgh J, et al. Fluid resuscitation with 6\% hydroxyethyl starch (13/0.4 and 130/0.42) in acutely ill patients: Systematic review of effects on mortality and treatment with renal 130/0.42) in acutely ill patients: Systematic review of effects on mortality and treatment with rena
replacement therapy. Intensive Care Med 2013;39(4):558-568. [http://dx.doi.org/10.1007/s00134-0132840-0]

12. Myburgh J. CHEST and the impact of fraud in fluid resuscitation research. Crit Care Resusc 2011;13(2):69-70.

13. Haase N, Perner A, Hennings LI, et al. Hydroxyethyl starch 130/0.38-0.45 versus crystalloid o albumin in patients with sepsis: Systematic review with meta-analysis and trial sequential analysis BMJ 2013;346:f839. [http://dx.doi.org/10.1136/bmj.f839]

14. Cowles M, Davis C. On the origins of the 0.05 level of statistical significance. Am Psychol 1982;37:553 558. http://www.radford.edu/ jaspelme/611/Spring-2007/Cowles-n-Davis_Am-Psyc_orignis-of-05level.pdf (accessed 15 April 2013).

15. Katz R. FDA: Evidentiary standards for drug development and approval. Neurotherapeutics 2004; 1:307-316.

16. Berger VW, Hsieh G. Rethinking statistics: basing efficacy alpha levels on safety data in randomised trials. Israeli Journal of Emergency Medicine 2005;5(3):55-60. http://www.isrjem.org/IJEM_Aug_ AlphaLevels_Proof.pdf (accessed 16 April 2013).

17. Alderson P, Bunn F, Lefebvre $C$, et al. Human albumin solution for resuscitation and volume expansion in critically ill patients. Cochrane Database Syst Rev 2002, Issue 1. Art. No. CD001208. [http://dx.doi. org $/ 10.1002 / 14651858 . C D 001208$

18. The SAFE Study Investigators. A comparison of albumin and saline for fluid resuscitation in the intensive care unit. N Engl J Med 2004;350(22):2247-2256. [http://dx.doi.org/10.1056 NEJMoa040232]

19. Moher D, Liberati A, Tetzlaff J, et al. Preferred reporting items for systematic reviews and meta-analyses: The PRISMA statement. Ann Intern Med 2009;151(4):264-269. [http://dx.doi.org/10.7326/0003-4819151-4-200908180-00135]

20. Hartog CS, Skupin H, Natanson C, et al. Systematic analysis of hydroxyethyl starch (HES) reviews: Proliferation of low-quality reviews overwhelms the results of well-performed meta-analyses. Intensive Care Med 2012;38(8):1258-1271. [http://dx.doi.org/10.1007/s00134-012-2614-0]

21. Lievre M, Cucherat M, Leizorovicz A. Pooling, meta-analysis and the evaluation of drug safety Current Controlled Trials in Cardiovascular Medicine 2002;3(1):6. [http://dx.doi.org/10.1186/1468-6708-3-6]

2 Martin C Jacob M, Vicaut $E_{\text {e }}$ et al. Effect of waxy maize-derived starch $130 / 0.4$ on ren function in function in surgical patients. Anesthesiology 2013;118(2):387-394. [http://dx.doi.org/10.1097/
ALN.0b013e31827e5569] 